\title{
Sleep-Dependent Consolidation of Auditory Discrimination Learning in Adult Starlings
}

\author{
Timothy P. Brawn, ${ }^{1}$ Howard C. Nusbaum, ${ }^{1}$ and Daniel Margoliash ${ }^{1,2}$ \\ Departments of ${ }^{1}$ Psychology and ${ }^{2}$ Organismal Biology and Anatomy, University of Chicago, Chicago, Illinois 60637
}

\begin{abstract}
Memory consolidation is widely believed to benefit from sleep. Sleep-dependent memory consolidation has been established broadly in humans, appearing in declarative and procedural tasks. Animal studies have indicated a variety of mechanisms that could potentially serve as the neural basis of sleep-dependent consolidation, such as the offline replay of waking neural activity and the modulation of specific sleep parameters or synaptic strength during sleep. Memory consolidation, however, cannot be inferred from neuronal events alone, and the behavioral demonstration of sleep-dependent consolidation has been limited in animals. Here we investigated whether adult animals undergo sleep-dependent memory consolidation comparable to that of humans. European starlings (Sturnus vulgaris) were trained to discriminate between segments of novel starling song and retested after retention periods that included a regular night of sleep or consisted only of wakefulness. Auditory discrimination performance improved significantly after retention periods that included sleep but not after time spent awake, and the performance changes following sleep were significantly greater than after comparable periods of wakefulness. Thus, sleep produces a pattern of memory benefits in adult starlings that is fundamentally similar to the patterns of sleep-dependent consolidation observed in humans, suggesting a common sleep-dependent mechanism works across many vertebrate species to consolidate memories and establishing a robust animal model for this phenomenon.
\end{abstract}

\section{Introduction}

Memory consolidation refers to the process whereby a newly formed memory trace is transformed from a labile state to a more stabilized form that is resistant to interference and possibly enhanced compared to the initial memory trace. The consolidation of memories is widely believed to benefit from sleep (Walker, 2005). Sleep-dependent performance benefits in humans have been demonstrated broadly, appearing in declarative (Ellenbogen et al., 2006; Fenn et al., 2009), spatial (Peigneux et al., 2004; Talamini et al., 2008), perceptual (Gais et al., 2000; Fenn et al., 2003), motor (Walker et al., 2002; Huber et al., 2004; Korman et al., 2007), and sensorimotor tasks (Robertson et al., 2004; Brawn et al., 2008).

Animal studies have indicated plausible neural mechanisms that could underlie sleep-dependent consolidation. Task learning can produce reliable changes in posttraining sleep parameters, such as increases in REM sleep (Smith, 1995), pontine wave density (Datta, 2000), sleep spindle density (Eschenko et al., 2006), and sharp wave ripple activity (Eschenko et al., 2008), which have been suggested to promote memory consolidation. Patterns of neural activity that are expressed during waking behaviors can be reactivated spontaneously during subsequent sleep (Wilson and McNaughton, 1994; Dave and Margoliash, 2000), a process that could act as a form of offline rehearsal and lead to stronger and

\footnotetext{
Received Aug. 27, 2009; revised 0ct. 13, 2009; accepted Nov. 17, 2009.

This work was supported by Grant DC007206 from the National Institute on Deafness and Other Communication Disorders.

Correspondence should be addressed to Timothy P. Brawn, University of Chicago, 1027 East 57th Street, Chicago, IL 60637. E-mail: tbrawn@uchicago.edu.

DOI:10.1523/JNEUROSCI.4237-09.2010

Copyright $\odot 2010$ the authors $\quad 0270-6474 / 10 / 300609-05 \$ 15.00 / 0$
}

more stable memory traces. Sleep-dependent changes in synaptic strength may also underlie consolidation. Synaptic strengthening during sleep is associated with sleep-dependent ocular dominance plasticity (Aton et al., 2009). Synaptic markers were also found to decrease during sleep (Gilestro et al., 2009), which may represent a process of synaptic downscaling that is hypothesized to improve the signal-to-noise ratio of newly formed memory traces (Tononi and Cirelli, 2006).

Nonetheless, memory consolidation cannot be inferred from neuronal events alone (Hennevin et al., 2007). Clear behavioral evidence of sleep-dependent consolidation has been limited in animals, mostly appearing in critical-period learning in juveniles (Derégnaucourt et al., 2005; Jackson et al., 2008; Shank and Margoliash, 2009), thereby potentially invoking learning mechanisms more prominent during development than in adults. To test whether newly formed memories are consolidated by sleep in adult animals, European starlings were trained to discriminate between segments of novel starling song and retested after retention periods that included a regular night of sleep or consisted only of wakefulness. The experimental design determined the effects of sleep and wakefulness on memory consolidation while ruling out confounding circadian factors. Additionally, every starling participated in each condition, producing a fully counterbalanced design, and starlings were engaged in a baseline discrimination task at all times outside of training and testing to further control for circadian confounds-features that cannot reasonably be achieved in human studies.

\footnotetext{
Materials and Methods

Subjects

Twenty-four adult starlings were maintained on a 16/8 light/dark schedule (lights on at 6:00 A.M.).
} 
Table 1. Time course of training and testing sessions for each condition

\begin{tabular}{|c|c|c|c|c|c|c|}
\hline Condition & Training & Posttraining test & Retention interval & Posttest I & Retention interval & Posttest 2 \\
\hline Wake & 7:45-9:45 A.M. & 10:00 A.M. & $9 \mathrm{~h}$ & 7:00 P.M. (day 1) & $X$ & $X$ \\
\hline Sleep & 4:45-6:45 P.M. & 7:00 P.M. & $15 \mathrm{~h}$ & 10:00 A.M. (day 2) & $x$ & $X$ \\
\hline $24 \mathrm{~h}-\mathrm{AM}$ & 7:45-9:45 A.M. & 10:00 A.M. & $24 \mathrm{~h}$ & 10:00 A.M. (day 2) & $X$ & $X$ \\
\hline $24 \mathrm{~h}-\mathrm{PM}$ & 4:45-6:45 P.M. & 7:00 P.M. & $24 \mathrm{~h}$ & 7:00 P.M. (day 2) & $X$ & $X$ \\
\hline AM-PM-AM & 7:45-9:45 A.M. & 10:00 A.M. & $9 \mathrm{~h}$ & 7:00 P.M. (day 1) & $15 \mathrm{~h}$ & 10:00 A.M. (day 2) \\
\hline PM-AM-PM & 4:45-6:45 P.M. & 7:00 P.M. & $15 \mathrm{~h}$ & 10:00 A.M. (day 2) & $9 \mathrm{~h}$ & 7:00 P.M. (day 2) \\
\hline
\end{tabular}

\section{Stimuli}

Thirteen stimulus pairs, each consisting of two $5 \mathrm{~s}$ segments of natural starling song, were recorded from seven starlings. One pair was recorded from one bird, and two pairs were recorded from each of six birds. The first pair was used in a practice session before the experimental sessions. Six pairs recorded from six different starlings were used in the six experimental conditions. The additional six pairs were used as back-up stimuli in cases where the experimental sessions had to be repeated due to computer or apparatus errors. The final stimulus pair consisted of a rising tone repeated three times versus a falling tone repeated three times, which was used during the baseline discrimination task (for stimulus spectrograms, see supplemental material, available at www.jneurosci.org).

\section{Procedures}

Familiarization procedures. Starlings were familiarized with the behavioral apparatus via a shaping procedure, and training and testing were accomplished using a go-nogo operant procedure (Gentner and Margoliash, 2003). Upon completing the shaping procedure, starlings began the gonogo task with the baseline stimulus pair. In the go-nogo procedure, the starling initiated stimulus playback by probing a response port with its beak. The starling responded to the stimulus by probing the port a second time or by withholding response. Responses during stimulus playback were ignored. The starling had $2 \mathrm{~s}$ to respond or to withhold from responding after stimulus playback ended. Responding to one stimulus $(\mathrm{S}+)$ resulted in $2 \mathrm{~s}$ of food access, whereas responding to the other stimulus $(\mathrm{S}-)$ resulted in the cage lights being extinguished for $10 \mathrm{~s}$. Nothing occurred if the starling did not respond to the stimulus.

Training sessions. Training consisted of a $2 \mathrm{~h}$ period during which starlings could complete up to 200 trials (for number of trials, see supplemental material, available at www.jneurosci.org). All responses to the $\mathrm{S}+$ stimulus resulted in a $2 \mathrm{~s}$ food reward. All responses to the $\mathrm{S}-\mathrm{stim}-$ ulus resulted in a $20 \mathrm{~s}$ lights-out punishment. The stimulus for each trial was selected randomly with the exception that correction trials were used during training. Thus, when a starling made an error (i.e., responded to an S- stimulus or withheld response to an S+ stimulus), the same stimulus was automatically selected for the next trial. The stimulus was again selected randomly if a starling made five consecutive errors. At the end of the $2 \mathrm{~h}$ training session, starlings received $15 \mathrm{~min}$ of ad libitum access to food.

Testing sessions. Testing sessions used the same stimulus pair as used during the training session and consisted of a $1 \mathrm{~h}$ period during which starlings could complete up to 50 trials. All responses to the $\mathrm{S}+$ stimulus resulted in a $2 \mathrm{~s}$ food reward. All responses to the $S-$ stimulus resulted in a $10 \mathrm{~s}$ lights-out punishment. Correction trials were not used during testing sessions. The stimulus for each trial was selected randomly but constrained so that each stimulus was selected 5 times for every 10 trials. This constraint ensured that both stimuli were selected on average an equal number of times during testing and limited the number of times that a single stimulus was selected consecutively. Test performance was measured as the percentage of correct trials, where a correct trial entailed responding to an $\mathrm{S}+$ stimulus or withholding response from an $\mathrm{S}-$ stimulus.

Baseline discrimination task. The starlings were engaged in a discrimination task with the baseline stimulus pair during all times that they were not involved in a testing or training session. Performance on the first 100 baseline trials following each test session was measured as an additional control for potential circadian confounds in auditory discrimination performance.
Table 2. Counterbalanced condition orders

\begin{tabular}{|c|c|c|c|c|c|c|}
\hline Subject & Session 1 & Session 2 & Session 3 & Session 4 & Session 5 & Session 6 \\
\hline Starling 01 & Wake & $24 \mathrm{~h}-\mathrm{AM}$ & Sleep & $24 \mathrm{~h}-\mathrm{PM}$ & PM-AM-PM & AM-PM-AM \\
\hline Starling 02 & Wake & $24 \mathrm{~h}-\mathrm{AM}$ & 24 h-PM & Sleep & AM-PM-AM & PM-AM-PM \\
\hline Starling 03 & Wake & Sleep & $24 \mathrm{~h}-\mathrm{AM}$ & 24 h-PM & AM-PM-AM & PM-AM-PM \\
\hline Starling 04 & Wake & Sleep & 24 h-PM & $24 \mathrm{~h}-\mathrm{AM}$ & PM-AM-PM & AM-PM-AM \\
\hline Starling 05 & Wake & 24 h-PM & $24 \mathrm{~h}-\mathrm{AM}$ & Sleep & AM-PM-AM & PM-AM-PM \\
\hline Starling 06 & Wake & 24 h-PM & Sleep & $24 \mathrm{~h}-\mathrm{AM}$ & PM-AM-PM & AM-PM-AM \\
\hline Starling 07 & Sleep & Wake & $24 \mathrm{~h}-\mathrm{AM}$ & $24 \mathrm{~h}-\mathrm{PM}$ & AM-PM-AM & PM-AM-PM \\
\hline Starling 08 & Sleep & Wake & 24 h-PM & $24 \mathrm{~h}-\mathrm{AM}$ & PM-AM-PM & AM-PM-AM \\
\hline Starling 09 & Sleep & $24 \mathrm{~h}-\mathrm{AM}$ & Wake & 24 h-PM & PM-AM-PM & AM-PM-AM \\
\hline Starling 10 & Sleep & $24 \mathrm{~h}-\mathrm{AM}$ & $24 \mathrm{~h}-\mathrm{PM}$ & Wake & AM-PM-AM & PM-AM-PM \\
\hline Starling I 1 & Sleep & $24 \mathrm{~h}-\mathrm{PM}$ & Wake & $24 \mathrm{~h}-\mathrm{AM}$ & AM-PM-AM & PM-AM-PM \\
\hline Starling 12 & Sleep & $24 \mathrm{~h}-\mathrm{PM}$ & $24 \mathrm{~h}-\mathrm{AM}$ & Wake & PM-AM-PM & AM-PM-AM \\
\hline Starling 13 & $24 \mathrm{~h}-\mathrm{AM}$ & Wake & Sleep & 24 h-PM & PM-AM-PM & AM-PM-AM \\
\hline Starling 14 & $24 \mathrm{~h}-\mathrm{AM}$ & Wake & 24 h-PM & Sleep & PM-AM-PM & AM-PM-AM \\
\hline Starling 15 & $24 \mathrm{~h}-\mathrm{AM}$ & Sleep & Wake & $24 \mathrm{~h}-\mathrm{PM}$ & AM-PM-AM & PM-AM-PM \\
\hline Starling 16 & $24 \mathrm{~h}-\mathrm{AM}$ & Sleep & 24 h-PM & Wake & AM-PM-AM & PM-AM-PM \\
\hline Starling 17 & $24 \mathrm{~h}-\mathrm{AM}$ & $24 \mathrm{~h}-\mathrm{PM}$ & Wake & Sleep & PM-AM-PM & AM-PM-AM \\
\hline Starling 18 & $24 \mathrm{~h}-\mathrm{AM}$ & 24 h-PM & Sleep & Wake & AM-PM-AM & PM-AM-PM \\
\hline Starling 19 & $24 \mathrm{~h}-\mathrm{PM}$ & Wake & Sleep & $24 \mathrm{~h}-\mathrm{AM}$ & PM-AM-PM & AM-PM-AM \\
\hline Starling 20 & $24 \mathrm{~h}-\mathrm{PM}$ & Wake & $24 \mathrm{~h}-\mathrm{AM}$ & Sleep & AM-PM-AM & PM-AM-PM \\
\hline Starling 21 & 24 h-PM & Sleep & Wake & $24 \mathrm{~h}-\mathrm{AM}$ & AM-PM-AM & PM-AM-PM \\
\hline Starling 22 & 24 h-PM & Sleep & $24 \mathrm{~h}-\mathrm{AM}$ & Wake & PM-AM-PM & AM-PM-AM \\
\hline Starling 23 & 24 h-PM & $24 \mathrm{~h}-\mathrm{AM}$ & Wake & Sleep & AM-PM-AM & PM-AM-PM \\
\hline Starling 24 & 24 h-PM & $24 \mathrm{~h}-\mathrm{AM}$ & Sleep & Wake & PM-AM-PM & AM-PM-AM \\
\hline
\end{tabular}

Every starling completed the six conditions in a unique order. In all cases, the four single-posttest conditions wer completed first, and the two double-posttest conditions were completed last.

\section{Experimental design}

Each starling participated in the six experimental conditions (Table 1), with two nights of sleep separating each condition. The first four conditions (single-posttest conditions) were completed in a unique order for each starling. The final two conditions (double-posttest conditions) were also counterbalanced (see Table 2 for unique condition orders). The retention intervals for the wake and sleep groups $(9$ and $15 \mathrm{~h}$, respectively) were not of equal duration to keep the testing times equivalent for all groups while also preventing the training or testing sessions from starting very early or late in the day. The stimulus pairs used in each respective condition were assigned randomly for each bird.

Practice session. Each starling completed a practice session to get accustomed to the training and testing sessions. In this session, starlings completed a training session with the practice stimulus pair from $7: 45$ to 9:45 A.M. and then completed testing sessions beginning at 10:00 A.M., 2:30 P.M., and 7:00 P.M. for the following $2 \mathrm{~d}$.

Experimental conditions. The first four experimental conditions (singleposttest) included a training session, a posttraining test, and a postretention test that occurred after either (1) a $9 \mathrm{~h}$ retention interval consisting of wakefulness (wake), (2) a $15 \mathrm{~h}$ retention interval that included a night of sleep (sleep), (3) a $24 \mathrm{~h}$ retention interval consisting of a day of wakefulness followed by a night of sleep ( $24 \mathrm{~h}-\mathrm{AM})$, or (4) a $24 \mathrm{~h}$ retention interval consisting of a night of sleep followed by a day of wakefulness (24 h-PM). The final two conditions (double-posttest; AM-PM-AM and PM-AM-PM) entailed a training session, a posttraining test, and two postretention tests occurring after a retention interval consisting of wakefulness and a retention interval including sleep. 
A

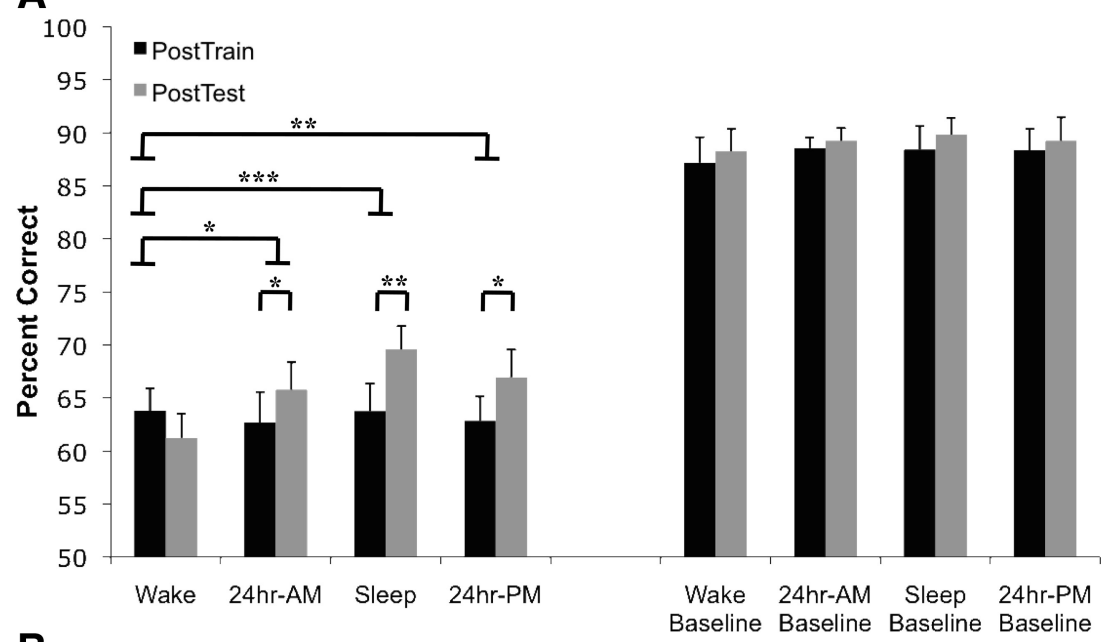

B

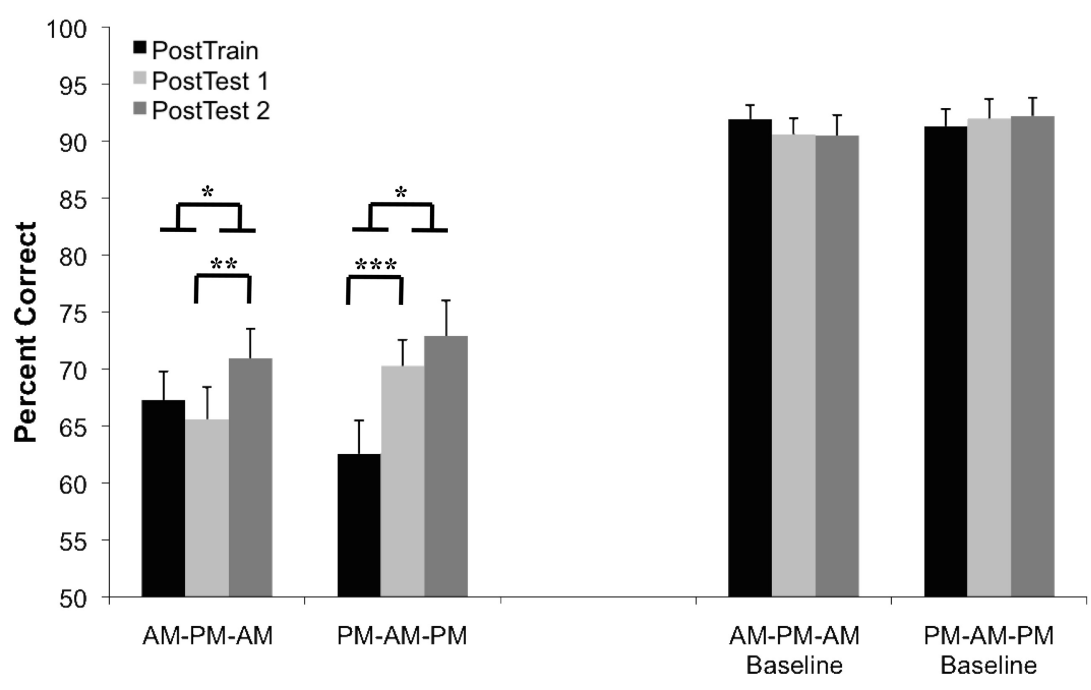

Figure 1. Performance accuracy. A, Performance was measured as the percentage of correct trials. For each pair of bars, the left/black bar denotes posttraining performance, and the right/gray bar denotes postretention performance. The leftmost four pairs of bars represent performance during the test sessions; the rightmost four pairs of bars represent the corresponding performance on the first 100 baseline trials after each test session. The three lowest significance bars show significant within-condition performance improvements. The significance bars at the three upper levels show that the performance improvement in the $24 \mathrm{~h}$-AM, sleep, and $24 \mathrm{~h}-\mathrm{PM}$ conditions were each significantly greater than the performance change in the wake condition. $\boldsymbol{B}$, For each set of three bars, the left/black bar denotes posttraining performance, the middle/light-gray bar denotes the first postretention test performance, and the right/dark-gray bar denotes the second postretention test performance. The leftmost two sets of bars represent performance during the test sessions, and the rightmost two sets of bars represent the corresponding performance on the first 100 baseline trials after each test session. The lower significance bars show significant performance improvements across the given retention interval. The upper significance bars show that the performance change across the sleep retention interval was significantly greater than the performance change across the wake retention interval in both conditions. Data are the means \pm SEM $\left({ }^{*} p<0.05 ;{ }^{* *} p<0.01 ;{ }^{* * *} p<0.001\right)$.

\section{Statistics}

A repeated-measures ANOVA was applied to detect differences in performance changes across the single-posttest conditions with plannedcomparison $t$ tests to check specific differences. Paired $t$ tests were applied to detect within-condition performance changes in the single- and doubleposttest conditions. A one-sample $t$ test was used to verify that posttraining performance was better than chance performance.

\section{Results}

Single training session produces robust learning

To investigate the behavioral effects of sleep on memory, starlings were trained on a go-nogo task to discriminate between a novel pair of $5 \mathrm{~s}$ starling song segments. Training was followed by both a posttraining test and a postretention test after an interval that either consisted entirely of wakefulness (wake) or included a night of sleep (24 h-AM, sleep, 24 h-PM) (see Table 1). Performance accuracy across all conditions on the posttraining test was $63.9 \pm$ $1.0 \%$ (mean $\pm \mathrm{SEM}$ ). This performance level was significantly greater than chance performance of 50\% $\left(t_{(143)}=13.29\right.$; $p<$ 0.0001 ), demonstrating that the single training session produced significant auditory discrimination learning in the starlings.

\section{Performance improves across sleep}

Performance changes across retention intervals were significantly different across the conditions $\left(F_{(3,69)}=4.52 ; p=0.006\right)$. Performance after waking retention decreased by $2.6 \pm 1.6$ percentage points from the posttraining to the postretention test $(63.8 \pm$ $2.2 \%$ to $61.2 \pm 2.6 \%$ ), representing a nonsignificant performance reduction after $9 \mathrm{~h}$ of wakefulness $\left(t_{(23)}=1.59 ; p=0.13\right)$ (Fig. 1A). By comparison, performance in the $24 \mathrm{~h}$-AM condition increased by $3.1 \pm$ 1.4 percentage points $(62.7 \pm 2.9 \%$ to $65.8 \pm 2.6 \%$ ), exhibiting a significant performance increase, without additional training, following a day of wakefulness and a night of sleep $\left(t_{(23)}=2.26 ; p=\right.$ $0.03)$. Performance in the sleep condition increased significantly by $5.8 \pm 1.7$ percentage points $(63.8 \pm 2.6 \%$ to $69.6 \pm 2.2 \%$ ) following a night of sleep $\left.t_{(23)}=3.49 ; p=0.002\right)$. Likewise, performance in the $24 \mathrm{~h}-\mathrm{PM}$ condition increased significantly by $4.1 \pm 1.9$ percentage points $(62.8 \pm 2.3 \%$ to $66.9 \pm 2.6 \%$ ) after a retention interval consisting of a night of sleep followed by a day of wakefulness $\left(t_{(23)}=2.21 ; p=\right.$ 0.04). Furthermore, the improvement in each condition that included a sleep period was significantly greater than the performance change in the wake condition $\left(24 \mathrm{~h}-\mathrm{AM}\right.$ vs wake, $t_{(47)}=2.43 ; p=$ 0.02 ; sleep vs wake, $t_{(47)}=3.60 ; p=$ $0.0008 ; 24$ h-PM vs wake, $t_{(47)}=2.87$; $p=0.006$ ) (Fig. 1A). Thus, these were robust effects.

To further test the effects of wakefulness and sleep on auditory discrimination learning, starlings were trained and retested after both a retention interval consisting of wakefulness and an interval including sleep. In the AM-PM-AM condition, performance decreased nonsignificantly by $1.7 \pm 1.9$ percentage points $(67.3 \pm 2.5 \%$ to $65.6 \pm 2.8 \%)$ across a day of wakefulness $\left(t_{(23)}=\right.$ $0.89 ; p=0.39)($ Fig. $1 B$ ) and then increased significantly by $5.3 \pm$ 2.2 percentage points $(65.6 \pm 2.8 \%$ to $70.9 \pm 2.6 \%)$ after a night of sleep $\left(t_{(23)}=2.95 ; p=0.007\right)$. The performance improvement across the sleep retention interval was significantly greater than across wakefulness $\left(t_{(23)}=2.14 ; p=0.04\right)$ (Fig. $\left.1 B\right)$. Notably, the overall performance change from the posttraining test to the following morning was $3.6 \pm 1.7$ percentage points, which is similar 
to the performance change of $3.1 \pm 1.4$ percentage points over the same interval in the $24 \mathrm{~h}$-AM condition.

In the PM-AM-PM condition, performance increased significantly by $7.7 \pm 1.8$ percentage points $(62.6 \pm 2.9 \%$ to $70.3 \pm 2.3 \%)$ across a night of sleep $\left(t_{(23)}=4.26 ; p=0.0003\right)$ (Fig. $1 B$ ) and then increased nonsignificantly by $2.6 \pm 1.7$ percentage points $(70.3 \pm 2.3 \%$ to $72.9 \pm 3.1 \%)$ across a day of wakefulness $\left(t_{(23)}=1.55 ; p=0.14\right)$. As before, the performance improvement across the sleep retention interval was significantly greater than across wakefulness $\left(t_{(23)}=2.35, p=\right.$ 0.03 ) (Fig. $1 B$ ). Interestingly, the performance change over the postsleep wake retention interval in the PM-AM-PM condition was significantly greater than the performance change over the presleep wake retention interval in the AM-PM-AM condition $\left(t_{(23)}=2.11 ; p=0.05\right)$.

\section{Lack of circadian effects}

We examined whether the apparent sleep-dependent consolidation was confounded by natural variation in auditory discrimination ability of starlings at different times of day. Combined posttraining performance for the morning training conditions (wake, $24 \mathrm{~h}-\mathrm{AM}$, and AM-PM-AM) and the evening training conditions (sleep, 24 h-PM, and PM-AM-PM) was similar, with performance levels of $64.6 \pm 1.5 \%$ and $63.1 \pm 1.5 \%$ for the two training times $\left(t_{(142)}=0.74 ; p=0.46\right)$. Likewise, there were no significant differences in posttraining performance across the six conditions $\left(F_{(5,115)}=0.85 ; p=0.52\right)$, demonstrating that the ability to learn auditory discriminations did not vary by training time. Furthermore, the starlings were engaged in a baseline auditory discrimination task during all times that they were not being trained or tested on the experimental stimuli. If the pattern of performance changes described above were due to circadian effects on performance, then a similar pattern should be apparent in the baseline discrimination task. The first 100 baseline trials following each test session were analyzed for accuracy, and there were no significant changes in baseline performance across the retention intervals for the single-posttest $\left(F_{(3,42)}=0.33 ; p=\right.$ 0.80 ) or double-posttest conditions (AM-PM-AM, $t_{(23)}=0.58$; $p=0.57$; PM-AM-PM, $\left.t_{(19)}=0.18 ; p=0.86\right)$. Accordingly, the beneficial effect of sleep cannot be explained by circadian factors on performance.

\section{Discussion}

\section{Sleep-dependent consolidation in animals}

We have demonstrated that auditory discrimination learning in starlings is consolidated by sleep. The relationship between sleep and memory has been studied extensively in animals, yet a clear presentation of sleep-dependent behavioral benefits similar to the benefits observed in humans has been lacking. Early studies documented increases in REM sleep duration following task learning in rodents (Smith, 1995), but these findings were inconsistent and inconclusive as to whether sleep produced behavioral benefits (Siegel, 2001). Studies in rats have revealed that odorreward association training increases sleep spindle density (Eschenko et al., 2006) and sharp-wave ripple activity (Eschenko et al., 2008) during posttraining sleep; nonetheless, it is unknown whether these increases produce subsequent behavioral improvements because performance was not assessed after sleep. More recently, error reduction in a spatial memory task was correlated with hippocampal sharp-wave ripple density in rats (Ramadan et al., 2009), yet the experimental design was substantially different from human behavioral studies, thus making comparisons of the behavioral benefits of sleep challenging.
Sleep-dependent learning has been reported in an electricshock avoidance task in rats and correlated with pontine wave density (Datta, 2000). The performance pattern was argued to represent sleep-dependent improvements by comparing avoidance accuracy during the first training block $(\sim 20 \%)$ with the first postsleep test block $(\sim 50 \%)$, yet performance clearly deteriorated from the end of training $(\sim 80 \%)$ to the beginning of testing ( $\sim 50 \%)$, making the claim of a sleep-dependent improvement problematic. Sleep has also been implicated in Pavlovian fear conditioning in mice (Cai et al., 2009). The freezing response after receiving footshocks degraded across the "awake" period and returned to the initial level after sleep. The role of sleep remains unclear, however, because mice sleep during a substantial portion $(35 \%)$ of the "awake" period.

Neural reactivation during sleep is commonly hypothesized as a mechanism for memory consolidation (Rasch and Born, 2007). Reactivation during sleep refers to a process whereby patterns of neural activity that are expressed during waking behaviors replay in a coordinated manner during subsequent sleep. Reactivation could enable the strengthening of the newly formed memory trace as well as the integration of the memory trace within existing networks (Marshall and Born, 2007). Reactivation has been established in a premotor area in zebra finches (Dave and Margoliash, 2000) and in the hippocampus (Wilson and McNaughton, 1994), visual cortex (Ji and Wilson, 2007) and medial prefrontal cortex (Peyrache et al., 2009) of rats. In these studies, behavioral performance was not assessed after sleep. Consequently, it is well established that learning can alter subsequent neural activity during sleep, but these changes are only tenuously linked to consolidation of a newly formed memory trace.

Sleep has been related to behavioral changes in two examples of critical-period learning in juveniles. The structure of vocalizations in juvenile zebra finches was shown to deteriorate immediately after sleep and then improve during intense morning singing, with the magnitude of nightly deterioration correlating with a more accurate tutor song imitation at the end of development (Derégnaucourt et al., 2005; Shank and Margoliash, 2009). Additionally, consolidation of a visual imprinting stimulus in the domestic chick was shown to require sleep (Jackson et al., 2008). Nonetheless, there are important differences between these developmental sleep-dependent changes and the pattern of results found in the current experiment. First, the immediate effect of sleep on song learning was performance deterioration; vocal structure only improved after intense morning practice, indicating the behavioral improvement resulted from the interaction of sleep and subsequent practice. In contrast, adult starlings exhibited sleep-dependent behavioral benefits at retest without additional practice. Second, consolidation of domestic chick imprinting was extremely sensitive to sleep timing and quality; consolidation was prevented if sleep did not begin within $5 \mathrm{~h}$ of imprinting exposure or if sleep was disturbed for only $1 \mathrm{~min}$ during successive half-hour intervals (Jackson et al., 2008). Yet, as also seen in human studies, sleep consolidated learning in starlings regardless of whether sleep onset began shortly after training or followed a day of wakefulness during which the starlings were engaged in a separate discrimination task. Finally, sleepdependent consolidation in zebra finches and domestic chicks was specific to the tutor song or imprinting stimulus. Starlings, however, learned and consolidated arbitrary segments of various song stimuli, suggesting that sleep-dependent consolidation may be a feature of a general learning process in vertebrates rather than being restricted to species-specific critical-period learning. 


\section{A common vertebrate pattern?}

The pattern of results described here is strikingly similar to the results observed in human sleep-dependent consolidation studies (Walker, 2005). Performance by starlings was enhanced on the morning following sleep and stable thereafter throughout the day, a common finding in human studies (Gais et al., 2000; Walker et al., 2002; Huber et al., 2004; Robertson et al., 2004; Korman et al., 2007). Moreover, starling performance showed evidence of decline across waking periods that occurred before sleep with recovery after sleep, a pattern that has also been shown in human studies (Fenn et al., 2003; Brawn et al., 2008). Although the waking performance deterioration in starlings did not reach significance, it was evident in both the wake and AM-PM-AM conditions, suggesting a repeatable, if weak, effect. The cause of waking performance deterioration in humans and starlings is uncertain, but interference from waking behavior and sensory stimulation is a plausible source. The performance decline in starlings may have failed to reach significance because the starlings only encountered familiar baseline stimuli during the day, thus limiting potential interference effects, whereas daytime behavior is uncontrolled in most human studies. Future studies will be able to address this potential interference effect as well other interesting behavioral questions such as whether sleep produces benefits that generalize to other similar auditory tasks (Fenn et al., 2003) or how sleep or time since sleep affects the learning rate of new tasks. Overall, the present results provide a clear behavioral demonstration of sleep-dependent consolidation in an adult animal, suggesting that a common sleep-dependent mechanism works across many vertebrate species to consolidate memories.

\section{References}

Aton SJ, Seibt J, Dumoulin M, Jha SK, Steinmetz N, Coleman T, Naidoo N, Frank MG (2009) Mechanisms of sleep-dependent consolidation of cortical plasticity. Neuron 61:454-466.

Brawn TP, Fenn KM, Nusbaum HC, Margoliash D (2008) Consolidation of sensorimotor learning during sleep. Learn Mem 15:815-819.

Cai DJ, Shuman T, Gorman MR, Sage JR, Anagnostaras SG (2009) Sleep selectively enhances hippocampus-dependent memory in mice. Behav Neurosci 123:713-719.

Datta S (2000) Avoidance task training potentiates phasic pontine-wave density in the rat: a mechanism for sleep-dependent plasticity. J Neurosci 20:8607-8613.

Dave AS, Margoliash D (2000) Song replay during sleep and computational rules for sensorimotor vocal learning. Science 290:812-816.

Derégnaucourt S, Mitra PP, Fehér O, Pytte C, Tchernichovski O (2005) How sleep affects the developmental learning of bird song. Nature 433:710-716.

Ellenbogen JM, Hulbert JC, Stickgold R, Dinges DF, Thompson-Schill SL (2006) Interfering with theories of sleep and memory: sleep, declarative memory, and associative interference. Curr Biol 16:1290-1294.

Eschenko O, Mölle M, Born J, Sara SJ (2006) Elevated sleep spindle density after learning or after retrieval in rats. J Neurosci 26:12914-12920.

Eschenko O, Ramadan W, Mölle M, Born J, Sara SJ (2008) Sustained in- crease in hippocampal sharp-wave ripple activity during slow-wave sleep after learning. Learn Mem 15:222-228.

Fenn KM, Nusbaum HC, Margoliash D (2003) Consolidation during sleep of perceptual learning of spoken language. Nature 425:614-616.

Fenn KM, Gallo DA, Margoliash D, Roediger HL 3rd, Nusbaum HC (2009) Reduced false memory after sleep. Learn Mem 16:509-513.

Gais S, Plihal W, Wagner U, Born J (2000) Early sleep triggers memory for early visual discrimination skills. Nat Neurosci 3:1335-1339.

Gentner TQ, Margoliash D (2003) Neuronal populations and single cells representing learned auditory objects. Nature 424:669-674.

Gilestro GF, Tononi G, Cirelli C (2009) Widespread changes in synaptic markers as a function of sleep and wakefulness in Drosophila. Science 324:109-112.

Hennevin E, Huetz C, Edeline JM (2007) Neural representations during sleep: from sensory processing to memory traces. Neurobiol Learn Mem $87: 416-440$.

Huber R, Ghilardi MF, Massimini M, Tononi G (2004) Local sleep and learning. Nature 430:78-81.

Jackson C, McCabe BJ, Nicol AU, Grout AS, Brown MW, Horn G (2008) Dynamics of a memory trace: effects of sleep on consolidation. Curr Biol 18:393-400.

Ji D, Wilson MA (2007) Coordinated memory replay in the visual cortex and hippocampus during sleep. Nat Neurosci 10:100-107.

Korman M, Doyon J, Doljansky J, Carrier J, Dagan Y, Karni A (2007) Daytime sleep condenses the time course of motor memory consolidation. Nat Neurosci 10:1206-1213.

Marshall L, Born J (2007) The contribution of sleep to hippocampusdependent memory consolidation. Trends Cogn Sci 11:442-450.

Peigneux P, Laureys S, Fuchs S, Collette F, Perrin F, Reggers J, Phillips C, Degueldre C, Del Fiore G, Aerts J, Luxen A, Maquet P (2004) Are spatial memories strengthened in the human hippocampus during slow wave sleep? Neuron 44:535-545.

Peyrache A, Khamassi M, Benchenane K, Wiener SI, Battaglia FP (2009) Replay of rule-learning related neural patterns in the prefrontal cortex during sleep. Nat Neurosci 12:919-926.

Ramadan W, Eschenko O, Sara SJ (2009) Hippocampal sharp wave/ripples during sleep for consolidation of associative memory. PLoS ONE 4:e6697.

Rasch B, Born J (2007) Maintaining memories by reactivation. Curr Opin Neurobiol 17:698-703.

Robertson EM, Pascual-Leone A, Press DZ (2004) Awareness modifies the skill-learning benefits of sleep. Curr Biol 14:208-212.

Shank SS, Margoliash D (2009) Sleep and sensorimotor integration during early vocal learning in a songbird. Nature 458:73-77.

Siegel JM (2001) The REM sleep-memory consolidation hypothesis. Science 294:1058-1063.

Smith C (1995) Sleep states and memory processes. Behav Brain Res 69:137-145.

Talamini LM, Nieuwenhuis ILC, Takashima A, Jensen O (2008) Sleep directly following learning benefits consolidation of spatial associative memory. Learn Mem 15:233-237.

Tononi G, Cirelli C (2006) Sleep function and synaptic homeostasis. Sleep Med Rev 10:49-62.

Walker MP (2005) A refined model of sleep and the time course of memory formation. Behav Brain Sci 28:51-64; discussion 64-104.

Walker MP, Brakefield T, Morgan A, Hobson JA, Stickgold R (2002) Practice with sleep makes perfect: sleep-dependent motor skill learning. Neuron 35:205-211.

Wilson MA, McNaughton BL (1994) Reactivation of hippocampal ensemble memories during sleep. Science 265:676-679. 